\title{
New $\mathrm{CHA}_{2} \mathrm{DS}_{2}$-VASc-HSF score predicts the no-reflow phenomenon after primary percutaneous coronary intervention in patients with ST-segment elevation myocardial infarction
}

\author{
Qin-Yao Zhang, Shu-Mei Ma*i] and Jia-Ying Sun
}

\begin{abstract}
Background: The no-reflow phenomenon (NRP) is a serious complication of primary percutaneous coronary intervention (PPCl) and is an independent predictor of poor prognosis. We aimed to find a simple but effective risk stratification method for the prediction of NRP.

Methods: This retrospective single-center study included 454 consecutive patients diagnosed with acute STsegment elevation myocardial infarction (STEMI) and treated by PPCl, who were admitted to our emergency department between January 2017 and March 2019. The patients were divided according to the post-PPCI thrombolysis in the myocardial infarction flow rate: the NRP group and the control group. The CHADS $2_{1} \mathrm{CHA}_{2} \mathrm{DS}_{2^{-}}$ VASc, and $\mathrm{CHA}_{2} \mathrm{DS}_{2}-\mathrm{VASC}-\mathrm{HSF}$ scores were calculated for all the patients in this study, and multivariable regression and receiver operating characteristic curve analyses were conducted to determine the independent predictors of NRP and the predictive value of the three scores.

Results: A total of 454 patients were analyzed in this study: 80 in the no-reflow group and 374 in the control group. The incidence of NRP was $17.6 \%$. Creatine kinase-myocardial band, Killip class, stent length, and multivessel disease also independently predicted NRP. The $\mathrm{CHA}_{2} \mathrm{DS}_{2}-\mathrm{VASc}-\mathrm{HSF}$ score had a higher predictive value than the other two scores, and a $\mathrm{CHA}_{2} \mathrm{DS}_{2}$-VASc-HSF score of $\geq 4$ predicted NRP with a sensitivity of $72.5 \%$ and specificity of $66.5 \%$ (area under the curve: 0.755, 95\% confidence interval [0.702-0.808]).

Conclusion: Although the $\mathrm{CHADS}_{2}, \mathrm{CHA}_{2} \mathrm{DS}_{2}-\mathrm{VASC}$, and $\mathrm{CHA}_{2} \mathrm{DS}_{2}-\mathrm{VASC}-\mathrm{HSF}$ scores can all be used as simple tools to predict NRP, our findings show that the $\mathrm{CHA}_{2} \mathrm{DS}_{2}$-VASc-HSF score had the highest predictive value. Thus, the $\mathrm{CHA}_{2} \mathrm{DS}_{2}$-VASC-HSF score may be an optimal tool for predicting high-risk patients.
\end{abstract}

Keywords: $\mathrm{CHA}_{2} \mathrm{DS}_{2}$-VASc-HSF score, ST-segment elevation myocardial infarction, Primary percutaneous coronary intervention, No-reflow phenomenon

\footnotetext{
* Correspondence: masm@sj-hospital.org

Department of Cardiology, Shengjing Hospital of China Medical University,

No.36, Sanhao Street, Heping District, Shenyang 110004, Liaoning, China
}

(c) The Author(s). 2020 Open Access This article is licensed under a Creative Commons Attribution 4.0 International License, which permits use, sharing, adaptation, distribution and reproduction in any medium or format, as long as you give appropriate credit to the original author(s) and the source, provide a link to the Creative Commons licence, and indicate if changes were made. The images or other third party material in this article are included in the article's Creative Commons licence, unless indicated otherwise in a credit line to the material. If material is not included in the article's Creative Commons licence and your intended use is not permitted by statutory regulation or exceeds the permitted use, you will need to obtain permission directly from the copyright holder. To view a copy of this licence, visit http://creativecommons.org/licenses/by/4.0/ The Creative Commons Public Domain Dedication waiver (http://creativecommons.org/publicdomain/zero/1.0/) applies to the data made available in this article, unless otherwise stated in a credit line to the data. 


\section{Background}

ST-segment elevation myocardial infarction (STEMI) is a common critical illness associated with coronary artery disease, for which primary percutaneous coronary intervention (PPCI) has become the preferred treatment strategy [1]. In some cases, despite adequate reopening of the culprit lesion, the ischemic myocardium still cannot obtain effective perfusion. This is known as the noreflow phenomenon (NRP), which renders PPCI less effective in patients with STEMI and is regarded as an independent predictor of short- and long-term morbidity and mortality $[2,3]$. Due to the lack of an established risk evaluation method, NRP occurs in up to $60 \%$ of patients with STEMI $[4,5]$. As a result, it is important to find a simple and effective risk stratification method for the prediction of NRP.

The $\mathrm{CHA}_{2} \mathrm{DS}_{2}$-VASc score (congestive heart failure, hypertension, age $[\geq 65=1$ point, $\geq 75=2$ points], diabetes, stroke/transient ischemic attack [TIA] [2 points], and vascular disease [peripheral arterial disease, previous myocardial infarction [MI] and aortic atheroma]) was developed from the $\mathrm{CHADS}_{2}$ score and has been used extensively to predict thromboembolic events in patients with nonvalvular atrial fibrillation and determine whether to use anticoagulant or antiplatelet drugs [6]. The components of these two scores are associated with atherosclerosis, vascular spasm, and microvascular dysfunction, which overlap the risk factors of NRP [7]. Several recent studies have also shown that the $\mathrm{CHA}_{2} \mathrm{DS}_{2}$ VASc scores are associated with the severity of coronary artery disease, its prognosis, and NRP in patients with acute MI, contrast-induced nephropathy after PPCI for acute coronary syndrome, in-stent restenosis, acute stent thrombosis, mechanical mitral valve thrombosis, and right ventricular dysfunction [8-16].

Recently, a new score, known as the $\mathrm{CHA}_{2} \mathrm{DS}_{2}$-VAScHSF score, was developed, which includes three new variables in addition to those comprising the $\mathrm{CHA}_{2} \mathrm{DS}_{2}$ VASc score: hyperlipidemia $(\mathrm{H})$, smoking $(\mathrm{S})$, and a family history of coronary heart disease (F). The female sex, as used in the previous scores, was also replaced by the male sex [17]. In the present study, we investigated whether the $\mathrm{CHADS}_{2}, \mathrm{CHA}_{2} \mathrm{DS}_{2}$-VASc, and $\mathrm{CHA}_{2} \mathrm{DS}_{2}$ VASc-HSF scores could predict NRP in patients with STEMI treated by PPCI and subsequently compared the accuracy of the three scores in predicting NRP.

\section{Methods}

\section{Study population}

This retrospective single-center study included 454 patients diagnosed with acute STEMI, treated by PPCI, and admitted to our emergency department between January 2017 and March 2019. The patients were divided into two groups according to the thrombolysis in the myocardial infarction (TIMI) flow grade after PPCI: The normal/slow-flow group comprised patients with a TIMI flow grade of $>2$, and the no-reflow group comprised patients with a TIMI flow grade of $\leq 2$, despite a successful reopening of the culprit vessel and a lack of mechanical obstructions that would reduce the coronary blood flow, such as thromboembolism, dissection, or spasm.

The diagnostic criteria for acute STEMI were as follows: (1) patients with typical angina symptoms lasting for more than $30 \mathrm{~min}$ and not totally relieved by nitroglycerin; (2) patients with a new ST-segment elevation in at least two contiguous leads, with elevation defined as $\geq 0.2 \mathrm{mV}$ in men or $\geq 0.15 \mathrm{mV}$ in women for leads $\mathrm{V} 2$ to V3 or $\geq 1 \mathrm{~mm}(0.1 \mathrm{mV})$ in the other leads or a new left bundle branch block; (3) patients with myocardial injury marker levels, including creatine kinase-myocardial band (CK-MB) or troponin higher than the normal upper limit within $12 \mathrm{~h}$ of the onset of symptoms; and (4) patients with symptoms that lasted less than $12 \mathrm{~h}$ [18]. The exclusion criteria were as follows: (1) patients who received thrombolytic therapy before PPCI; (2) patients in whom stent implantation was rejected; (3) patients with percutaneous coronary angioplasty only; and (4) patients with severe liver or kidney dysfunction. Patient data, including demographics and clinical characteristics, angiographic features, and laboratory findings, were obtained from the hospital records. This study was approved by our ethics committee and was given the ethical number 2019 ps602k, with the number of people at 460 . The TIMI flow grades are classically defined as follows: grade 0 , no antegrade blood flow through the vascular occlusion; grade 1, a small amount of contrast agent can pass through the stenosis but cannot fill the distal coronary bed; grade 2, the contrast agent can fill the distal coronary bed, but the filling speed is slow; and grade 3, the contrast agent fills the distal coronary bed quickly and completely [19]. The TIMI flow grade was evaluated by two cardiologists who were blinded to the study. The frame rate of the cine images was 30 frames/s. The Killip grades are Class I patients who did not show evidence of heart failure (HF). Class II patients presented mild to moderate heart failure, but wet snoring occurred in less than $50 \%$ of the two lung fields. Class III patients exhibited severe heart failure, the presence of wet sputum was greater than $50 \%$ of both lungs, and acute pulmonary edema was a possibility. Class IV consisted of patients with cardiogenic shock [20].

All patients received $300 \mathrm{mg}$ of aspirin and $600 \mathrm{mg}$ of clopidogrel at the time of the diagnosis of STEMI in our emergency department. Coronary angiography was performed using standard techniques. PPCI was performed via the radial artery as the first choice. The patients were immediately given heparin $(80-100 \mathrm{U} / \mathrm{kg})$ when the 
culprit vessel was defined and the intervention decision was made. All PPCIs were performed for the culprit vessel only and according to the lesion anatomy and electrocardiogram, including balloon dilation and stent implantation. Thrombus aspiration and tirofiban infusion were applied according to the operator's choice. The treatment was considered successful when the coronary artery stenosis was $<50 \%$ and the antegrade blood flow of the infarct-related artery achieved a TIMI flow grade of 2 or 3 after PPCI was performed.

\section{Clinical and laboratory data}

We also collected each patient's medical history, family history, and laboratory dates. Their previous history included hypertension, diabetes mellitus, smoking history, congestive heart failure, stroke, transient ischemic attack, a history of MI, peripheral arterial disease, and complex aortic plaques. Hypertension was defined as a history of hypertension and the use of antihypertensive drugs or the repeated measurement of systolic blood pressure (SBP) $\geq 140 \mathrm{mmHg}$ and diastolic blood pressure (DBP) $\geq 90 \mathrm{mmHg}$. Diabetes mellitus was defined as a previous diagnosis of diabetes mellitus and the use of insulin or antidiabetic agents or a fasting glucose level of $>126$ $\mathrm{mg} / \mathrm{dL}$. Smoking history was defined as smoking at least one cigarette every day for more than 1 year without cessation. Congestive heart failure was defined as a previous diagnosis of heart failure. Each patient's family history of coronary heart disease was determined as follows: more than one first-degree relative with heart disease aged $\leq 55$ years for men and $\leq 65$ years for women.

The laboratory data included hyperlipidemia (a total cholesterol [TC] level of $>200 \mathrm{mg} / \mathrm{dL}$ or low-density lipoprotein cholesterol [LDL-C] level of $>160 \mathrm{mg} / \mathrm{dL}$ ), hemoglobin (men 130-172 g/L, women 110-150 g/L), creatinine (men 59-104 $\mu \mathrm{mol} / \mathrm{L}$, women $45-84 \mu \mathrm{mol} / \mathrm{L}$ ), eGFR, $\left(90-120 \mathrm{ml} / \mathrm{min} / 1.73 \mathrm{~m}^{2}\right)$, glycosylated hemoglobin (4.8-6.0\%), cardiac troponin I [cTnI] $(0.01-0.23 \mathrm{ng} / \mathrm{L})$, creatine kinase-myocardial band (CK-MB) (2.0-7.2 ng/ L), NT-pro brain natriuretic peptide (NT-pro BNP) $(300-450 \mathrm{pg} / \mathrm{mL})$, and left ventricular ejection fraction (LVEF) $(50-70 \%)$.

\section{Statistical analysis}

Normally distributed continuous variables were expressed as mean $\pm \mathrm{SD}$, and group differences were evaluated using the independent-samples $t$-test. Categorical variables were defined as frequencies and percentages, and group differences were evaluated using the Chi-square or Fisher exact test, as appropriate.

Univariate and multivariate analyses were performed to identify the predictors of NRP. Particularly, indicators that may have affected NRP were entered into the univariate logistic regression analyses. However, individual components of the $\mathrm{CHA}_{2} \mathrm{DS}_{2}$-VASc-HSF score and the $\mathrm{CHADS}_{2}$ and $\mathrm{CHA}_{2} \mathrm{DS}_{2}$-VASc scores were not entered into the multivariate analysis to avoid multicollinearity. The predictive power of the individual components of the $\mathrm{CHA}_{2} \mathrm{DS}_{2}$-VASc-HSF score was also evaluated using multivariate logistic regression. The results of the regression analyses were presented as odds ratios (ORs) with a 95\% confidence interval (CI).

Finally, the sensitivity and specificity of the $\mathrm{CHADS}_{2}$, $\mathrm{CHA}_{2} \mathrm{DS}_{2}$-VASc, and $\mathrm{CHA}_{2} \mathrm{DS}_{2}$-VASc-HSF scores in predicting NRP were evaluated at various cut-off values using receiver operating characteristic (ROC) curves. DeLong's test was used to compare the areas under the curve (AUCs) for the three scores.

A two-sided $p$-value $<0.05$ was considered statistically significant. The statistical analyses were performed using SPSS 22.0 software (SPSS Inc., Chicago, IL, USA), except for the comparisons of the AUCs of the three scores, which were performed using MedCalc Statistical software, version 15.6 (MedCalc Software, Ostend, Belgium).

\section{Results}

A total of 454 patients were analyzed: 80 patients in the noreflow group and 374 patients in the control group. The incidence of NRP was $17.6 \%$. The patients' demographic characteristics, clinical features, and laboratory findings are summarized in Table 1. There were no group differences in SBP, DBP, heart rate, TC, high-density lipoprotein cholesterol (HDL-C), LDL-C, NT-pro brain natriuretic peptide, hemoglobin, glycosylated hemoglobin, cardiac troponin I, and pain-to-balloon time among the patients. Compared to those of the normal/slow-flow group, the no-reflow group had lower eGFR and LVEF, higher CK-MB and creatinine, and a prevalence of Killip class $>1$.

The $\mathrm{CHADS}_{2}, \mathrm{CHA}_{2} \mathrm{DS}_{2}$-VASc, and $\mathrm{CHA}_{2} \mathrm{DS}_{2}$-VAScHSF scores were significantly higher in the no-reflow group than in the normal/slow-flow group. Four components of the $\mathrm{CHA}_{2} \mathrm{DS}_{2}$-VASc-HSF score-age, a history of stroke/TIA, hypertension, and vascular disease-were higher in the no-reflow group than in the normal/slowflow group. Other components of the $\mathrm{CHA}_{2} \mathrm{DS}_{2}$-VAScHSF score, including female sex, diabetes mellitus, a history of heart failure, smoking, hyperlipidemia, and family history, did not differ between the groups.

The patients' angiographic characteristics are shown in Table 2. Between the no-reflow and normal/slow-flow groups, there was no difference in the patients' culprit vessels, the prevalence of an initial TIMI flow grade of $0-1$, multi-stent, stent length, stent diameter, the use of tirofiban infusion, the use of thrombus aspiration, and the use of an intra-aortic balloon pump. However, multivessel disease was more common in the no-reflow group than in the normal/slow-flow group, but there was no statistical difference. 
Table 1 Demographic characteristics, clinical features, and laboratory findings

\begin{tabular}{|c|c|c|c|}
\hline Variables & Normal/slow-flow $(n=374)$ & No-reflow $(n=80)$ & $P$ value \\
\hline Age, years, mean (SD) & $59.10(11.61)$ & $63.21(11.64)$ & $0.004^{*}$ \\
\hline Female sex, n (\%) & $98(26.2)$ & $18(22.5)$ & 0.491 \\
\hline Hypertension, n (\%) & $158(42.2)$ & $44(55.0)$ & $0.037^{*}$ \\
\hline Diabetes mellitus, n (\%) & $79(23.4)$ & 25(31.3) & 0.143 \\
\hline History of heart failure, n (\%) & $3(0.8)$ & $1(1.3)$ & 0.539 \\
\hline History of stroke/TIA, n (\%) & $30(8.0)$ & $17(21.3)$ & $<0.001^{*}$ \\
\hline Vascular disease, n (\%) & $58(15.5)$ & $30(37.5)$ & $<0.001^{*}$ \\
\hline Smoking, n (\%) & $216(57.8)$ & $50(62.5)$ & 0.434 \\
\hline Hyperlipidemia, n (\%) & $97(25.9)$ & $29(36.3)$ & 0.061 \\
\hline Family history, n (\%) & $48(12.8)$ & $17(21.3)$ & 0.051 \\
\hline eGFR, ml/min $/ 1.73 \mathrm{~m}^{2}$, mean (SD) & 95.92(23.87) & $86.25(23.46)$ & $0.001^{*}$ \\
\hline SBP, mmHg, mean (SD) & 121.86(18.99) & 117.83(18.20) & 0.083 \\
\hline $\mathrm{DBP}, \mathrm{mmHg}$, mean (SD) & $76.51(12.64)$ & $75.54(12.34)$ & 0.530 \\
\hline HR, beats/min, mean (SD) & $77.58(13.47)$ & $77.18(14.87)$ & 0.809 \\
\hline $\mathrm{TC}$, mmol/L, mean (SD) & $4.66(1.06)$ & $4.76(1.06)$ & 0.417 \\
\hline $\mathrm{HDL}-\mathrm{C}, \mathrm{mmol} / \mathrm{L}$, mean (SD) & $1.01(0.27)$ & $1.08(0.26)$ & 0.052 \\
\hline LDL-C, mmol/L, mean (SD) & 2.99(0.90) & $3.04(0.87)$ & 0.665 \\
\hline Creatinine, $\mu \mathrm{mol} / \mathrm{L}$, mean (SD) & $69.95(18.95)$ & $78.35(25.18)$ & $0.006^{*}$ \\
\hline hemoglobin, g/L, mean (SD) & $141.08(17.28)$ & $141.31(15.20)$ & 0.911 \\
\hline glycosylated hemoglobin, \%, mean (SD) & $6.30(1.45)$ & $6.59(1.53)$ & 0.109 \\
\hline CTnl, ng/L, mean (SD) & $1.26(4.92)$ & $4.46(11.84)$ & $0.02^{*}$ \\
\hline CK-MB, ng/L, mean (SD) & 44.30(74.92) & $80.26(103.50)$ & $0.004^{*}$ \\
\hline NT-pro BNP, pg/mL, mean (SD) & 694.97(2102.8) & 1071.8(2519.7) & 0.170 \\
\hline Pain-to-balloon time, $h$, mean (SD) & $5.94(3.42)$ & $6.44(2.67)$ & 0.214 \\
\hline $\mathrm{CHADS}_{2}$ score, mean (SD) & $1.08(1.04)$ & $1.76(1.20)$ & $<0.001^{*}$ \\
\hline $\mathrm{CHA}_{2} \mathrm{DS}_{2}$-VASc score, mean (SD) & $1.61(1.38)$ & $2.60(1.58)$ & $<0.001^{*}$ \\
\hline $\mathrm{CHA}_{2} \mathrm{DS}_{2}$-VASc-HSF score, mean (SD) & $3.06(1.24)$ & $4.34(1.26)$ & $<0.001^{*}$ \\
\hline LVEF, \%, mean (SD) & $56.62(8.02)$ & $52.87(9.52)$ & $0.005^{*}$ \\
\hline \multicolumn{4}{|l|}{ Killip class, n (\%) } \\
\hline 1 & $304(81.3)$ & $56(70.0)$ & \multirow[t]{2}{*}{$0.024^{*}$} \\
\hline$>1$ & 70(18.7) & $24(30.0)$ & \\
\hline
\end{tabular}

Abbreviations: eGFR estimated glomerular filtration rate, TIA transient ischemic attack, SBP systolic blood pressure, DBP diastolic blood pressure, $H R$ heart rate, $T C$ total cholesterol, HDL-C high-density lipoprotein cholesterol, LDL-C low density lipoprotein cholesterol, $c T n /$ cardiac troponin I, CK-MB creatine kinase-myocardial band, NT-pro BNP NT-pro brain natriuretic peptide, LVEF left ventricular ejection fraction, SD standard deviation $* P<0.05$

The results of the regression analyses for the predictors of NRP are shown in Table 3. From the multivariate regression analysis, CK-MB, Killip class, stent length, multivessel disease, tirofiban infusion, and the $\mathrm{CHA}_{2} \mathrm{DS}_{2}$-VASc-HSF score were independent predictors of NRP. The $\mathrm{CHADS}_{2}$ and $\mathrm{CHA}_{2} \mathrm{DS}_{2}$-VASc scores were also independent predictors of NRP after adjusting for CK-MB, age, LVEF, eGFR, stent length, stent diameter, multivessel disease, tirofiban infusion, and Killip class (as shown in Table 4). The results of the regression analyses for the individual components of the $\mathrm{CHA}_{2} \mathrm{DS}_{2}$-VAScHSF score are shown in Table 5 . In the multivariate regression analysis, the male sex, hypertension, age 65 to 74 years, age $\geq 75$ years, a history of stroke/TIA, vascular disease, family history, and hyperlipidemia were found to be independently associated with NRP.

The ROC curve analyses revealed that a $\mathrm{CHADS}_{2}$ score of $\geq 2$ had a sensitivity of $56.3 \%$ and a specificity of 68.2\% (AUC: $0.664,95 \% \mathrm{CI}[0.60-0.73]$ ). $\mathrm{A} \mathrm{CHA}_{2} \mathrm{DS}_{2}$ VASc score of $\geq 2$ was also shown to have a sensitivity of $75.0 \%$ and a specificity of $53.7 \%$ (AUC: $0.682,95 \%$ CI [0.62-0.74]). Finally, a $\mathrm{CHA}_{2} \mathrm{DS}_{2}$-VASc-HSF score of $\geq 4$ had a sensitivity of $72.5 \%$ and a specificity of $65.0 \%$ (AUC: $0.755,95 \%$ CI $[0.70-0.81]$ ), and the score of $\geq 6$ 
Table 2 Angiographic features

\begin{tabular}{|c|c|c|c|}
\hline Variables & Normal/slow-flow $(n=374)$ & $\begin{array}{l}\text { No-reflow } \\
(n=80)\end{array}$ & $P$ value \\
\hline Culprit vessel, n (\%) & & & 0.765 \\
\hline LM & $3(0.8)$ & $1(1.3)$ & \\
\hline LAD & $228(61.0)$ & $53(66.3)$ & \\
\hline RCA & 104(27.8) & $18(22.5)$ & \\
\hline LCX & $39(10.4)$ & $8(10.0)$ & \\
\hline Multivessel disease, n (\%) & 135(36.1) & $38(47.5)$ & 0.057 \\
\hline Initial TIMl flow grade, n (\%) & & & 0.321 \\
\hline $0-1$ & $300(80.2)$ & 68(19.8) & \\
\hline$\geq 2$ & $74(85.0)$ & $12(15.0)$ & \\
\hline Multistent, n (\%) & 153(40.9) & $29(36.3)$ & 0.440 \\
\hline Stent length, mm, mean (SD) & 39.62(19.83) & 43.69(20.33) & 0.098 \\
\hline Stent diameter, $\mathrm{mm}$, mean (SD) & $3.23(0.46)$ & $3.20(0.42)$ & 0.582 \\
\hline Tirofiban infusion, n (\%) & 190(50.8) & $49(61.3)$ & 0.089 \\
\hline Thrombus aspiration, n (\%) & $17(4.5)$ & $7(8.8)$ & 0.127 \\
\hline IABP, n (\%) & $9(2.4)$ & $5(6.3)$ & 0.071 \\
\hline
\end{tabular}

Abbreviations: $L M$ Left main, $L A D$ Left anterior descending, $L C X$ Left circumflex, $R C A$ Right coronary artery, IABP intra-aortic balloon pump, $M I$ myocardial infarction, $T I M I$ thrombolysis in myocardial infarction, $S D$ standard deviation

had a specificity of $100 \%$ in the prediction of NRP. The ROC curves are shown in Fig. 1. The results of pairwise comparisons in the AUCs are shown in Table 6. The $\mathrm{CHA}_{2} \mathrm{DS}_{2}$-VASc-HSF score was, therefore, found to be the best score for predicting NRP.

In this study, 239 patients used tirofiban during PPCI. Of these, for the AUC of the no-reflow ROC curve, the $\mathrm{CHA}_{2} \mathrm{DS}_{2}$-VASc-HSF score was 0.763 (95\% CI [0.694$0.833]$ ). A $\mathrm{CHA}_{2} \mathrm{DS}_{2}$-VASc-HSF score of $\geq 4$ was the best cut-off value, with a sensitivity of $0.755 \%$ and specificity of $0.632 \%$. Conversely, 215 patients did not use tirofiban. A $\mathrm{CHA}_{2} \mathrm{DS}_{2}$-VASc-HSF score of $\geq 4$ yielded a sensitivity and specificity of 0.677 and $0.668 \%$, respectively (AUC: 0.741 ,
95\% CI [0.657-0.826]). In both groups, the $\mathrm{CHA}_{2} \mathrm{DS}_{2}$ VASc-HSF scores are similar predictors of NRP.

\section{Discussion}

This study demonstrates that the $\mathrm{CHADS}_{2}, \mathrm{CHA}_{2} \mathrm{DS}_{2}$ VASc, and $\mathrm{CHA}_{2} \mathrm{DS}_{2}$-VASc-HSF scores are all independent predictors of NRP after PPCI in patients with STEMI. However, the new $\mathrm{CHA}_{2} \mathrm{DS}_{2}$-VASc-HSF score was found to be a better predictor of NRP than the other two scores, and a score of $\geq 4$ can be used as a cut-off value, with a sensitivity of $72.5 \%$ and a specificity of $65.0 \%$. To our knowledge, this is the first study to evaluate the new $\mathrm{CHA}_{2} \mathrm{DS}_{2}$-VASc-HSF score in terms of

Table 3 Results of the univariate and multivariate regression analyses for the predictors of the no-reflow phenomenon

\begin{tabular}{lllll}
\hline Variables & Unadjusted OR(95\% Cl) & $P$ value & Adjusted OR(95\% Cl) & $P$ value \\
\hline LVEF & $0.95(0.92-0.98)$ & 0.002 & $0.98(0.94-1.03)$ & 0.428 \\
Age & $1.03(1.01-1.06)$ & 0.005 & $0.991(0.953-1.03)$ & 0.664 \\
CK-MB & $1.004(1.002-1.007)$ & 0.001 & $1.007(1.003-1.012)$ & 0.002 \\
eGFR & $0.982(0.971-0.993)$ & 0.001 & $0.98(0.97-1.003)$ & 0.093 \\
Killip class & $1.86(1.08-3.21)$ & 0.025 & $0.101(0.02-0.54)$ & 0.007 \\
Stent length & $1.01(0.998-1.02)$ & 0.10 & $1.03(1.01-1.05)$ & 0.012 \\
Stent diameter & $0.86(0.504-1.47)$ & 0.581 & $0.87(0.38-2.04)$ & 0.755 \\
Multivessel disease & $1.007(0.61-1.67)$ & 0.979 & $0.014(0.003-0.08)$ & $<0.001$ \\
Tirofiban infusion & $1.53(0.94-2.51)$ & 0.091 & $0.23(0.07-0.73)$ & 0.012 \\
CHA $_{2}$ DS $_{2}$-VASC-HSF score & $2.21(1.78-2.75)$ & $<0.001$ & $31.31(12.53-78.26)$ & $<0.001$ \\
\hline
\end{tabular}

Abbreviations: $C K-M B$ creatine kinase-myocardial band, eGFR estimated glomerular filtration rate, $O R$ odds ratio, $L V E F$ left ventricular ejection fraction, $C I$ confidence interval 
Table 4 Results of the univariate and multivariate regression analyses for the predictive power of the $\mathrm{CHADS}_{2}, \mathrm{CHA}_{2} \mathrm{DS}_{2}-\mathrm{VASC}$, $\mathrm{CHA}_{2} \mathrm{DS}_{2}$-VASc-HSF scores

\begin{tabular}{lllll}
\hline Variables & Unadjusted OR $(95 \% \mathrm{Cl})$ & $P$ value & Adjusted OR(95\% Cl) & $P$ value \\
\hline CHADS $_{2}$ score & $1.698(1.37-2.11)$ & $<0.001$ & $2.35(1.59-3.46)$ & $<0.001$ \\
$\mathrm{CHA}_{2} \mathrm{DS}_{2}$-VASC score & $1.55(1.31-1.82)$ & $<0.001$ & $1.80(1.35-2.41)$ & $<0.001$ \\
$\mathrm{CHA}_{2} \mathrm{DS}_{2}$-VASc-HSF score & $2.21(1.78-2.75)$ & $<0.001$ & $31.31(12.53-78.26)$ & $<0.001$ \\
\hline
\end{tabular}

$O R$ odds ratio, $\mathrm{Cl}$ confidence interval

predicting NRP and comparing the prediction ability of the three scores.

As one of the serious complications of PPCI, NRP can aggravate myocardial ischemia and increase MI size and the incidence of heart failure, in addition to also being an independent predictor of short- and long-term adverse prognoses $[4,5,21]$. The exact mechanism of NRP is still not fully understood, but the mainstream view is that microvascular obstruction, including ischemic injury, reperfusion injury, microvascular dysfunction, and distal microvascular embolization, is the main pathological basis of NRP [4]. Currently, there are few effective therapies for this complication, and no standard treatment has been established to date. Some studies have suggested that a deferring stent has a lower rate of NRP than an immediate stent [22]. Most cardiologists believe that preventing NRP is more effective than treating it. Thus, it is important to determine a simple and effective risk stratification method for NRP that would enable physicians to specify individualized treatment plans before conducting stenting in patients.

The guidelines recommend using the $\mathrm{CHA}_{2} \mathrm{DS}_{2}$-VASc score for stroke risk stratification in patients with atrial fibrillation. However, the components of the $\mathrm{CHA}_{2} \mathrm{DS}_{2^{-}}$ VASc score-such as hypertension, diabetes, and ageare well-accepted major risk factors for atherosclerosis. Consistent with this, several previous studies have shown that the $\mathrm{CHA}_{2} \mathrm{DS}_{2}$-VASc score is a predictor of the severity of coronary artery disease [17, 23]. $\mathrm{Li}$ et al. [24] also reported that the $\mathrm{CHA}_{2} \mathrm{DS}_{2}$-VASc score is a powerful predictor of major adverse cardio-cerebral vascular events in patients with acute MI, while Wang et al. [10] found that deaths after long-term illnesses, cardiac deaths, and non-fatal strokes are significantly higher in patients with a $\mathrm{CHA}_{2} \mathrm{DS}_{2}$-VASc score of $>2$ than in patients with a lower $\mathrm{CHA}_{2} \mathrm{DS}_{2}$-VASc score. Significantly, another previous study concluded that the $\mathrm{CHA}_{2} \mathrm{DS}_{2}$ VASc score is independently associated with NRP and all-cause, in-hospital mortality, [25] which may indicate that the score further predicts patients' prognoses by predicting NRP. Consistent with this, some of the components of the $\mathrm{CHA}_{2} \mathrm{DS}_{2}$-VASc score are associated with microvascular dysfunction, such as hypertension, diabetes, female sex, and aortic stenosis [26, 27]. Atherosclerosis, heart failure, advanced age, and peripheral vascular disease are additional known risk factors for NRP [28]. Thus, the overlapping of risk factors and shared pathophysiologic pathways may be the reason the $\mathrm{CHA}_{2} \mathrm{DS}_{2}$-VASc score can predict both the prognosis and ischemic events such as NRP in patients. Several other studies have confirmed that the $\mathrm{CHA}_{2} \mathrm{DS}_{2}$-VASc score is an independent predictor of NRP [28-30], and a recent meta-analysis revealed that male sex, a family history of coronary artery disease, and smoking are also

Table 5 Results of the univariate and multivariate regression analyses for the predictive power of the individual components of the $\mathrm{CHA}_{2} \mathrm{DS}_{2}$-VASC-HSF score

\begin{tabular}{lllll}
\hline Variables & Unadjusted OR(95\% Cl) & $P$ value & Adjusted OR(95\% Cl) & $P$ value \\
\hline Male sex & $0.82(0.46-1.45)$ & 0.491 & $0.48(0.22-0.99)$ & 0.048 \\
Hypertension & $1.67(1.03-2.71)$ & 0.038 & $1.82(1.04-3.18)$ & 0.035 \\
Age 65-74 years & $2.19(1.26-3.82)$ & 0.006 & $3.33(1.76-6.32)$ & $<0.001$ \\
Age $\geq 75$ years & $2.86(1.43-5.71)$ & 0.003 & $5.52(2.37-12.87)$ & $<0.001$ \\
Diabetes mellitus & $1.697(0.995-2.895)$ & 0.052 & $1.73(0.95-3.17)$ & 0.076 \\
History of heart failure & $1.57(0.16-15.2)$ & 0.70 & $2.06(0.18-23.99)$ & 0.563 \\
History of stroke/TIA & $1.76(1.27-2.44)$ & 0.001 & $2.11(1.45-3.07)$ & $<0.001$ \\
Vascular disease & $3.27(1.92-5.57)$ & $<0.001$ & $4.37(2.39-7.99)$ & $<0.001$ \\
Smoking & $1.22(0.74-2.004)$ & 0.435 & $1.77(0.93-3.38)$ & 0.08 \\
Hyperlipidemia & $1.62(0.97-2.71)$ & 0.063 & $2.71(1.499-4.92)$ & 0.001 \\
Family history & $1.83(0.99-3.39)$ & 0.054 & $2.67(1.299-5.50)$ & 0.008 \\
\hline
\end{tabular}

Abbreviations: TIA transient ischemic attack, OR odds ratio, $\mathrm{Cl}$ confidence interval 


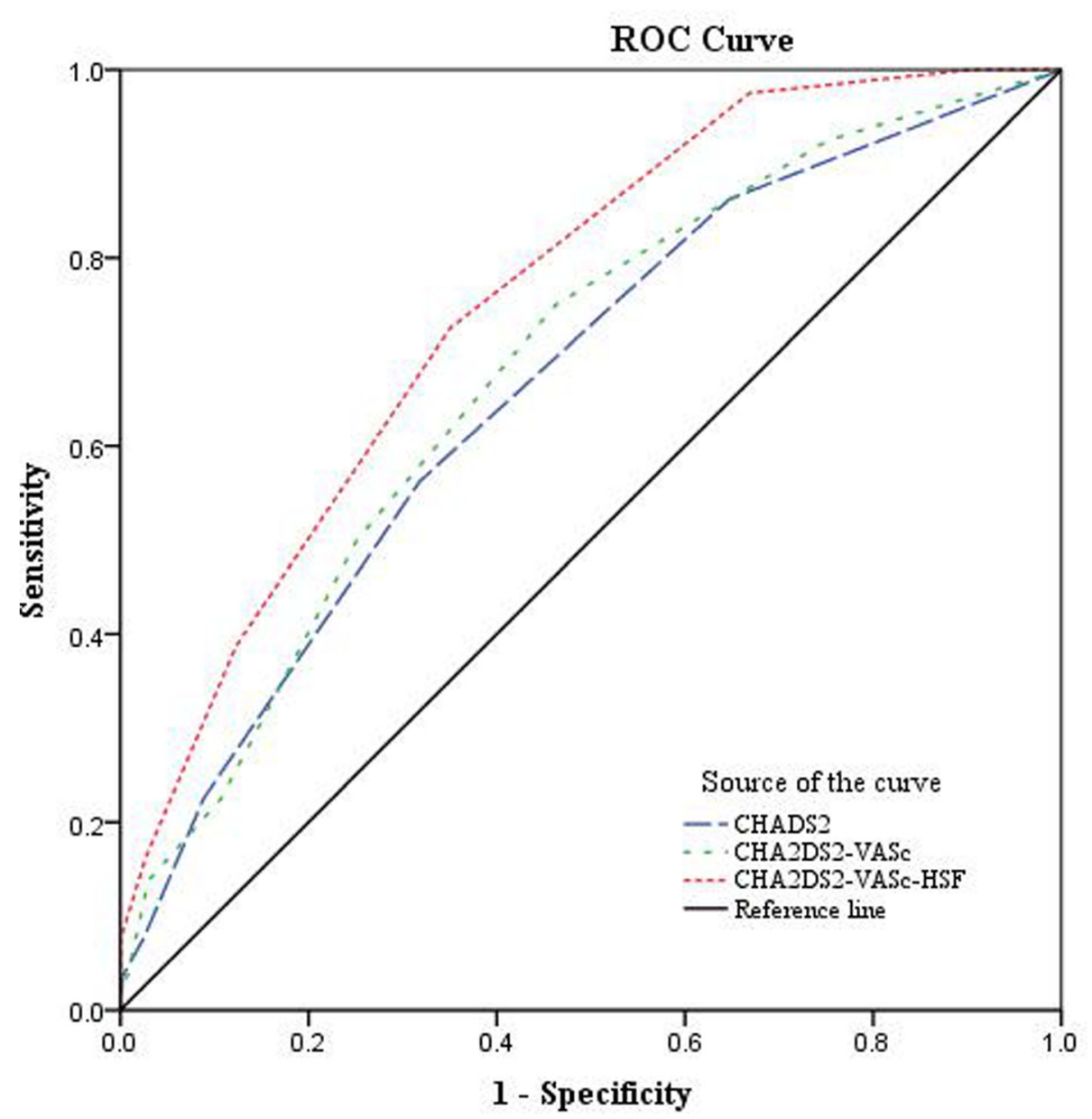

Fig. 1 Receiver operating characteristic (ROC) curves of the $\mathrm{CHADS}_{2}, \mathrm{CHA}_{2} \mathrm{DS}_{2}-\mathrm{VASC}$, and $\mathrm{CHA}_{2} \mathrm{DS} \mathrm{S}_{2}-\mathrm{VASc}-\mathrm{HSF}$ scores in the prediction of the no-reflow phenomenon

associated with NRP [31]. Thus, we sought to evaluate the ability of the new $\mathrm{CHA}_{2} \mathrm{DS}_{2}$-VASc-HSF score to independently predict NRP and compare the prediction ability of the three scores.

Previous studies have identified various predictors of NRP. For example, Bayramoglu et al. [32] and Mazhar et al. [33] found that advanced age, lower-left ventricular ejection fraction, stent length of $\geq 20 \mathrm{~mm}$, thrombus burden, Killip class $\geq 3$, and longer pain-to-balloon time are independent predictors of NRP. Similarly, anterior infarctions, [34] hypertension, dyslipidemia, a history of smoking, and a history of tobacco use [35] have also been shown to be associated with NRP. In the present study, we demonstrated that Killip class, stent length, and CK-MB are independent predictors of NRP. We also found that multivessel disease, tirofiban infusion, a history of stroke/TIA, family history, and vascular disease are associated with NRP and that the $\mathrm{CHA}_{2} \mathrm{DS}_{2}$-VASc score is an independent predictor of NRP, which is consistent with the findings of previous studies [28-30].

In this study, the multivariate regression analysis did not reveal diabetes mellitus to be a predictor of NRP. A previous study also found that NRP was more likely in patients with hyperglycemia upon hospital admission, while there was no difference in glycosylated hemoglobin or the incidence of diabetes mellitus [36]. Diabetes

Table 6 Pairwise comparisons of the areas under the receiver operating characteristics curve

\begin{tabular}{|c|c|c|c|c|c|}
\hline Score & Difference between areas & Standard error & 95\% Confidence interval & Z Statistic & $P$ value \\
\hline $\mathrm{CHADS}_{2}$ vs $\mathrm{CHA}_{2} \mathrm{DS}_{2}$-VASC & 0.0173 & 0.0182 & $-0.018-0.053$ & 0.95 & 0.3419 \\
\hline $\mathrm{CHADS}_{2} \mathrm{VSCHA}_{2} \mathrm{DS}_{2}$-VASc-HSF & 0.0907 & 0.025 & $0.042-0.140$ & 3.629 & 0.0003 \\
\hline $\mathrm{CHA}_{2} \mathrm{DS}_{2}-\mathrm{VASC}$ VS $\mathrm{CHA}_{2} \mathrm{DS}_{2}-\mathrm{VASC}-\mathrm{HSF}$ & 0.0734 & 0.0275 & $0.0194-0.127$ & 2.666 & 0.0077 \\
\hline
\end{tabular}


mellitus is mainly a risk factor of atherosclerosis and is associated with coronary stenosis and microvascular dysfunction. Some studies have also confirmed that diabetes is associated with NRP [37]. In contrast, hyperglycemia may be involved in vascular smooth muscle cell proliferation and migration, oxidative stress, hypercoagulable state, and inflammatory response [38]. Thus, both are associated with the mechanism of NRP, but we believe that it is more likely that admission hyperglycemia is associated with NRP rather than diabetes mellitus. As such, prospective studies with large sample sizes are needed to further clarify this association.

In the present study, male sex was also revealed to be an independent predictor of NRP. A previous study reported that young women with STEMI are more likely than similarly aged men to have reperfusion delays and that the female sex is associated with NRP [39]. This may be due to several factors, such as differences in plaque composition and thrombotic activity between men and women and a higher prevalence of microvascular disease in women than in men. Recently, a meta-analysis of 27 studies found that the male sex is an independent predictor of NRP, which is consistent with the results of the present study. We believe that the male sex may be more closely related to no-reflow; therefore, we changed the female sex in the $\mathrm{CHA}_{2} \mathrm{DS}_{2}$ VASc score to the male sex, which increased the predictive value. This may be because male patients are more likely to smoke and suffer from obesity than female patients.

In the emergency department, STEMI is a common critical illness that requires immediate revascularization. However, if NRP occurs after PPCI, it is dangerous for patients, and treatment is challenging. Thus, a simple and established tool is needed for risk stratification. In the present cohort study, we found that the $\mathrm{CHADS}_{2}$ and $\mathrm{CHA}_{2} \mathrm{DS}_{2}$-VASc scores, as well as the new $\mathrm{CHA}_{2} \mathrm{DS}_{2}$-VASc-HSF score, can be independent predictors of NRP since the components of these scores are common risk factors of atherosclerosis, vascular spasm, and microvascular dysfunction, as well as NRP and stroke. Finally, we found that $\mathrm{CHA}_{2} \mathrm{DS}_{2}$-VASc-HSF scores of $\geq 4$ had a maximum predictive value, and the specificity was $100 \%$ for $\mathrm{CHA}_{2} \mathrm{DS}_{2}$-VASc-HSF scores of $\geq 6$, which may be helpful in clinic settings.

\section{Study limitations}

The present study has some limitations. It had a singlecenter, retrospective observational design, and therefore the number of patients analyzed was relatively small. Bias may also exist as the data were mainly based on a review of the previous clinical history of patients in an acute clinical setting. Thus, the calculation of the three scores may have been affected. We did not collect data regarding in-hospital mortality, nor did we conduct patient follow-ups to determine long-term mortality and adverse cardiac events. We had no data regarding pharmacological treatment during or before the procedure, which might influence the achievement of a final TIMI 3 flow. We also had no data regarding the frequency of thrombus aspiration or the use of an intraaortic balloon pump during PPCI.

\section{Conclusions}

We found that the $\mathrm{CHADS}_{2}, \mathrm{CHA}_{2} \mathrm{DS}_{2}$-VASc, and $\mathrm{CHA}_{2} \mathrm{DS}_{2}$-VASc-HSF scores are all independent predictors of NRP, but the new $\mathrm{CHA}_{2} \mathrm{DS}_{2}$-VASc-HSF score has higher sensitivity and specificity than the other scores. Thus, the $\mathrm{CHA}_{2} \mathrm{DS}_{2}$-VASc-HSF score may be a simple tool for the prediction of patients at high risk of NRP. Future prospective studies with larger samples are needed to support these results.

\section{Abbreviations}

NRP: No-reflow phenomenon; PPCl: Primary percutaneous coronary intervention; STEMI: ST-segment elevation myocardial infarction; CKMB: Creatine kinase-myocardial band; HF: Heart failure; TIMI: Thrombolysis in the myocardial infarction; SBP: Systolic blood pressure; DBP: Diastolic blood pressure; TC: Total cholesterol; LDL-C: Low-density lipoprotein cholesterol: NT-pro BNP: NT-pro brain natriuretic peptide; LVEF: Left ventricular ejection fraction; SD: Standard deviation; ORs: Odds ratios; Cl: Confidence interval; ROC: Receiver-operating characteristics; AUCs: Areas under the curve; HDLC: High-density lipoprotein cholesterol

\section{Acknowledgements}

We would like to acknowledge the hard and dedicated work of all the staff that implemented the intervention and evaluation components of the study.

\section{Authors' contributions}

SMM and JYS conceived the idea and conceptualised the study. QYZ and JYS collected the data. SMM analysed the data. QYZ and SMM drafted the manuscript, then SMM reviewed the manuscript. All authors read and approved the final draft.

\section{Funding}

No external funding received to conduct this study.

\section{Availability of data and materials}

The datasets generated and/or analysed during the current study are not publicly available due to the lack of an online platform but are available from the corresponding author on reasonable request.

\section{Ethics approval and consent to participate}

I confirm that I have read the Editorial Policy pages. This study was conducted with approval from the Ethics Committee of Shengjing Hospital of China medical University. This study was conducted in accordance with the declaration of Helsinki.

\section{Consent for publication}

Not applicable.

\section{Competing interests}

The authors declare that they have no competing interests.

Received: 25 December 2019 Accepted: 13 July 2020

Published online: 25 July 2020

\section{References}

1. Levine GN, Bates ER, Blankenship JC, Bailey SR, Bittl JA, Cercek B, et al. 2015 ACC/AHA/SCAI focused update on primary percutaneous coronary intervention for patients with ST-elevation myocardial infarction: an update of the 2011 ACCF/AHA/SCAI guideline for percutaneous coronary 
intervention and the 2013 ACCF/AHA guideline for the management of STelevation myocardial infarction. J Am Coll Cardiol. 2016;67:1235-50.

2. Somuncu MU, Akgun T, Cakir MO, Akgul F, Serbest NG, Karakurt H, et al. The elevated soluble ST2 predicts no-reflow phenomenon in ST-elevation myocardial infarction undergoing primary percutaneous coronary intervention. J Atheroscler Thromb. 2019;26:970-8.

3. Zhao Y, Yang J, Ji Y, Wang S, Wang T, Wang F, et al. Usefulness of fibrinogen-to-albumin ratio to predict no-reflow and short-term prognosis in patients with ST-segment elevation myocardial infarction undergoing primary percutaneous coronary intervention. Heart Vessel. 2019;34:1600-7.

4. Bouleti C, Mewton N, Germain S. The no-reflow phenomenon: state of the art. Arch Cardiovasc Dis. 2015;108:661-74.

5. Karimianpour A, Maran A. Advances in coronary no-reflow phenomenon-a contemporary review. Curr Atheroscler Rep. 2018;20:44.

6. Lip GY, Nieuwlaat R, Pisters R, Lane DA, Crijns HJ. Refining clinical risk stratification for predicting stroke and thromboembolism in atrial fibrillation using a novel risk factor-based approach: the euro heart survey on atrial fibrillation. Chest. 2010;137:263-72.

7. Chan YH, Yiu KH, Lau KK, Yiu YF, Li SW, Lam TH, et al. The CHADS2 and CHA2DS2-VASC scores predict adverse vascular function, ischemic stroke and cardiovascular death in high-risk patients without atrial fibrillation: role of incorporating PR prolongation. Atherosclerosis. 2014;237:504-13.

8. Bozbay M, Uyarel H, Cicek G, Oz A, Keskin M, Murat A, et al. CHA2DS2-VASC score predicts in-hospital and long-term clinical outcomes in patients with ST-segment elevation myocardial infarction who were undergoing primary percutaneous coronary intervention. Clin Appl Thromb Hemost. 2017;23: $132-8$.

9. Trantalis G, Aggeli K, Toutouzas K, Synetos A, Latsios G, Drakopoulou M, et al. The prognostic value of CHA2DS2-VASC and GRACE risk scores in patients with ACS. Hell J Cardiol. 2018:60:1-4.

10. Wang X, Pei C, Bai Y, Dai Q, Deng X, Liu Y, et al. Predictive value of CHA2DS2-VASC score for ischemic events in patients undergoing percutaneous coronary intervention. Angiology. 2018;70:878-86.

11. Wegiel M, Rakowski T, Dziewierz A, Wojtasik-Bakalarz J, Sorysz D, Bartus S, et al. CHA2DS2-VASC and R2-CHA2DS2-VASC scores predict in-hospital and post-discharge outcome in patients with myocardial infarction. Postepy Kardiol Interwencyjnej. 2018;14:391-8.

12. Kurtul A, Yarlioglues M, Duran M. Predictive value of CHA2DS2-VASC score for contrast-induced nephropathy after percutaneous coronary intervention for acute coronary syndrome. Am J Cardiol. 2017;119:819-25.

13. Kurtul A. Usefulness of the CHA2DS2-VASC score in predicting in-stent restenosis among patients undergoing revascularization with bare-metal stents. Clin Appl Thromb Hemost. 2018;24(4):589-95.

14. Gök M, Kurtul A, Harman M, Kara M, Süleymanoglu M, Ornek E. Relationship between CHA2DS2-VASC score and right ventricular dysfunction in patients with acute pulmonary thromboembolism. Clin Appl Thromb Hemost. 2018: 1076029618785771. https://doi.org/10.1177/1076029618785771.

15. Tanık VO, Aruğaslan E, Çinar T, et al. Association of the CHA2DS2VASc score with acute stent thrombosis in patients with an ST elevation myocardial infarction who underwent a primary percutaneous coronary intervention. Med Princ Pract. 2019;28(2):115-23.

16. Çınar T, Hayıroğlu MI, Tanık VO, et al. The predictive value of the CHA2DS2VASC score in patients with mechanical mitral valve thrombosis. J Thromb Thrombolysis. 2018;45(4):571-7.

17. Modi R, Patted SV, Halkati PC, Porwal S, Ambar S, Mr P, et al. CHA2DS2VASC-HSF score - new predictor of severity of coronary artery disease in 2976 patients. Int J Cardiol. 2017;228:1002-6.

18. Nair Rajesh G, Jayaprasad N, Madhavan S, et al. Predictors and prognosis of no-reflow during primary percutaneous coronary intervention. Proc (Baylor Univ Med Cent). 2018;32:30-3.

19. TIMI Study Group. Definitions used in TIMI trials. Available at: http://www. timi.org. Accessed 20 June 2009.

20. Killip T, Kimball JT. Treatment of myocardial infarction in a coronary care unit: a two year experience of 250 patients. Am J Cardiol. 1967;20:457-64.

21. Ndrepepa G, Tiroch K, Keta D, et al. Predictive factors and impact of noreflow after primary percutaneous coronary intervention in patients with acute myocardial infarction. Circ Cardiovasc Intervent. 2010;3:27-33.

22. Carrick D, Oldroyd KG, McEntegart M, Haig C, Petrie MC, Eteiba H, et al. A randomized trial of deferred stenting versus immediate stenting to prevent no- or slow-reflow in acute ST-segment elevation myocardial infarction (DEFER-STEMI). J Am Coll Cardiol. 2014;63:2088-98.
23. Cetin M, Cakici M, Zencir C, Tasolar H, Baysal E, Balli M, et al. Prediction of coronary artery disease severity using CHADS2 and CHA2DS2-VASC scores and a newly defined CHA2DS2-VASC-HS score. Am J Cardiol. 2014;113:950-6.

24. Li CY, Chang CJ, Chung WJ, Lin CJ, Hsueh SK, Lee CH, et al. Assessment of CHA2DS2-VASC score for predicting cardiovascular and cerebrovascular outcomes in acute myocardial infarction patients. Medicine (Baltimore). 2018;97:e11230

25. Ashoori A, Pourhosseini H, Ghodsi S, Salarifar M, Nematipour E, Alidoosti M, et al. CHA2DS2-VASC Score as an independent predictor of suboptimal reperfusion and short-term mortality after primary $\mathrm{PCl}$ in patients with acute ST segment elevation myocardial infarction. Medicina (Kaunas). 2019:55:35.

26. Crea F, Camici PG, Bairey Merz CN. Coronary microvascular dysfunction: an update. Eur Heart J. 2014;35:1101-11.

27. Sara JD, Taher R, Kolluri N, Vella A, Lerman LO, Lerman A. Coronary microvascular dysfunction is associated with poor glycemic control amongst female diabetics with chest pain and non-obstructive coronary artery disease. Cardiovasc Diabetol. 2019;18:22.

28. Avci E, Yildirim T, Aydin G, Kiris T, Dolapoglu A, Kadi H, et al. Combining clinical predictors to better predict for the no-reflow phenomenon. Eur Rev Med Pharmacol Sci. 2018:22:4987-94.

29. Ipek G, Onuk T, Karatas MB, Gungor B, Osken A, Keskin M, et al. CHA2DS2VASC score is a predictor of no-reflow in patients with ST-segment elevation myocardial infarction who underwent primary percutaneous intervention. Angiology. 2016;67:840-5.

30. Mirbolouk F, Gholipour M, Salari A, Shakiba M, Kheyrkhah J, Nikseresht V, et al. CHA2DS2-VASC score predict no-reflow phenomenon in primary percutaneous coronary intervention in primary percutaneous coronary intervention. J Cardiovasc Thorac Res. 2018;10:46-52.

31. Fajar JK, Heriansyah T, Rohman MS. The predictors of no reflow phenomenon after percutaneous coronary intervention in patients with ST elevation myocardial infarction: a meta-analysis. Indian Heart J. 2018;70: S406-18.

32. Bayramoglu A, AUID- Oho, Tasolar H, Kaya A, Tanboga IH, Yaman M, et al. Prediction of no-reflow and major adverse cardiovascular events with a new scoring system in STEMl patients. J Interv Cardiol. 2018;31:144-9.

33. Mazhar J, Mashicharan M, Farshid A. Predictors and outcome of no-reflow post primary percutaneous coronary intervention for ST elevation myocardial infarction. Int J Cardiol Heart Vasc. 2016;10:8-12.

34. Hassan A, Mohamed H, Mohamed AM, Ahmed T, Kishk YT. Predictors of noreflow in patients undergoing primary percutaneous coronary intervention. Thrombus aspiration was protective. Egypt Heart J. 2018;70:421-6.

35. Sanghvi S, Mathur R, Baroopal A, Kumar A. Clinical, demographic, risk factor and angiographic profile of coronary slow flow phenomenon: a single centre experience. Indian Heart J. 2018;70:S290-4.

36. Iwakura K, Ito H, Ikushima M, Kawano S, Okamura A, Asano K, et al. Association between hyperglycemia and the no-reflow phenomenon in patients with acute myocardial infarction. J Am Coll Cardiol. 2003:41:1-7.

37. Celik T, Kaya MG, Akpek M, Gunebakmaz O, Balta S, Sarli B, et al. Predictive value of admission platelet volume indices for in-hospital major adverse cardiovascular events in acute ST-segment elevation myocardial infarction. Angiology. 2015;66:155-62.

38. Bessonov IS, Kuznetsov VA, Potolinskaya W, Zyrianov IP, Sapozhnikov SS. Impact of hyperglycemia on the results of percutaneous coronary interventions in patients with acute ST-segment elevation myocardial infarction. Ter Arkh. 2017;89:25-9.

39. Celik T, Balta S, Ozturk C, Kaya MG, Aparci M, Yildirim OA, et al. Predictors of no-reflow phenomenon in young patients with acute ST-segment elevation myocardial infarction undergoing primary percutaneous coronary intervention. Angiology. 2016;67:683-9.

\section{Publisher's Note}

Springer Nature remains neutral with regard to jurisdictional claims in published maps and institutional affiliations. 